DOI: $10.19177 /$ reen.v12e3201950-74

\title{
CADEIA DE VALOR E VANTAGENS COLABORATIVAS: ESTUDO EM UM PROCESSO DE IMPORTAÇÃO DE UMA CARGA CONTEINERIZADA
}

\section{VALUE CHAIN AND COLLABORATIVE ADVANTAGES: STUDY IN A PROCESS OF IMPORTATION OF A CONTAINERIZED LOAD}

\section{CADENA DE VALOR Y VENTAJAS COLABORATIVAS: ESTUDIO EN UN PROCESO DE IMPORTACIÓN DE UNA CARGA CONTENERIZADA}

\section{Caio de Araújo Pereira Gadelha}

Mestrando em Engenharia de Produção pela Universidade Federal da Paraíba (UFPB) Endereço: R. Sebastião de Azevedo Bastos, n. 496, CEP: 58038-491. Manaíra, SC, Brasil Telefone: (083) 9 9104-8052

E-mail: caio_gad@hotmail.com

\section{Cláudia Fabiana Gohr}

Doutora em Engenharia de Produção pela Universidade Federal de Santa Catarina (UFSC)

Professora do Programa de Pós-Graduação em Engenharia de Produção e de Administração da UFPB Endereço: UFPB, Departamento de Engenharia de Produção, Campus I, Bloco G, CEP: 58051-970. João Pessoa, PB, Brasil Telefone: (83) 3216-7549

E-mail: claudiagohr@ct.ufpb.br

\section{Maria Silene Alexandre Leite}

Doutora em Engenharia de Produção pela UFSC

Docente do Programa de Pós-Graduação em Engenharia de Produção da UFPB

Endereço: UFPB, Departamento de Engenharia de Produção, Campus I, Bloco G, CEP: 58051-970.

João Pessoa, PB, Brasil

Telefone: (83) 3216-7549

E-mail: mariasileneleite@hotmail.com

\section{Melca Farias Vieira}

Sócia Diretora da F3 Trading Comércio Importação e Exportação Ltda

Endereço: R. Maria das Dores Souza, n. 60. Cabo Branco, João Pessoa, PB, Brasil

Telefone: (083) 9 9991-6921

E-mail: melca@f3importexport.com.br

Artigo recebido em 10/03/2019. Revisado por pares em 15/06/2019. Reformulado em 20/06/2019. Recomendado para publicação em 10/12/2019. Publicado em 23/12/2019. Avaliado pelo Sistema double blind review. 


\section{RESUMO}

Este artigo tem como objetivo analisar as atividades e os recursos da cadeia de um processo de importação de uma carga conteinerizada, utilizando como suporte teórico a Cadeia de Valor, a Visão Baseada em Recursos e a Visão Relacional visando verificar se estes permitem o desenvolvimento de rendas relacionais. Para tanto, foi desenvolvido um estudo de caso cujo principal instrumento de coleta de dados foi a entrevista. Foi possível constatar que há recursos e atividades da cadeia de valor que contribuem para a geração de rendas relacionais provenientes, principalmente, da confiança e dotação de recursos complementares entre as duas empresas.

Palavras-chave: Cadeia de valor; Rendas relacionais; Visão baseada em recurso; Comércio marítimo.

\section{ABSTRACT}

This article has as objective to analyze the activities and resources of the chain of a process of import of a containerized cargo, using as theoretical support the Value Chain, the Resource Based View and the Relational View in order to verify if these allow the development of relational rents. For that, a case study was developed whose main instrument of data collection was the interview. It was possible to verify that there are resources and activities of the value chain that contribute to the generation of relational rents, mainly coming from the trust and complementary resource allocation between the two companies.

Keywords: Value chain; Relational rents; Resource-based view; Maritime trade.

\section{RESUMEN}

El trabajo tuvo como objetivo analizar las actividades y los recursos de la cadena de un proceso de importación de una carga contenerizada, utilizando como soporte teórico la Cadena de Valor, la Visión Basada en Recursos y la Visión Relacional para verificar si estos permiten el desarrollo de rentas relacionales. Para ello, se desarrolló un estudio de caso cuyo principal instrumento de recolección de datos fue la entrevista. Es posible constatar que hay recursos y actividades de la cadena de valor que contribuyen a la generación de rentas relacionales provenientes principalmente de la confianza y dotación de recursos complementarios entre las empresas.

Palabras-clave: Cadena de valor; Rentas relacionales; Visión basada en el recurso; Comercio marítimo 


\section{INTRODUÇÃO}

No atual mundo globalizado, tem se tornado cada vez mais importante as empresas conhecerem toda a cadeia do seu produto, uma vez que buscam agregar o máximo de valor ao cliente. Em muitas indústrias, a competição não acontece mais entre empresas individuais, e sim, entre cadeias de suprimentos. Partindo dessa premissa, o próximo desafio em estudos de gestão estratégica é analisar as cadeias de suprimentos para identificar as fontes de vantagem competitiva sustentável (FEIZ ABADI; CORDON, 2012).

Em cadeias de suprimentos, o conceito de cadeia de valor tem ganhado importância e se refere às atividades realizadas por uma empresa ao longo da cadeia. Toda empresa é uma reunião de atividades que são executadas para projetar, produzir, comercializar, entregar e sustentar seu produto. Esse conjunto de atividades, pode ser demonstrado através de sua cadeia de valor (PORTER, 1991).

Embora as empresas individualmente tenham sido foco de análise na literatura estratégica, hoje, em um mundo de alianças e coalizações, a concorrência ocorre cada vez mais entre cadeias de suprimentos (WILK; FENSTERSEIFER, 2003). Tais cadeias de suprimentos são conectadas por cadeias de valores dentro de um processo. Halldorsson et al. (2007) afirmam que a Gestão da Cadeia de Suprimentos está em constante mudança, porque as empresas buscam um melhor desempenho na produção e entrega de bens e serviços, porém grande parte da criação de valor desses processos ocorre fora das fronteiras da firma.

Nesse contexto, apesar de o ambiente de negócios ser o mesmo para todas as empresas, existe uma necessidade de entender por que algumas cadeias possuem melhores desempenhos do que outras. Barney (1991) considera que são os recursos que levam as empresas a terem melhor desempenho operacional do que outras conforme sugere a visão baseada em recursos (VBR). Para a VBR as firmas são capazes de criar e manter vantagem competitiva através da coleta e integração de recursos raros, valiosos, não imitáveis e não substituíveis (BARNEY, 1991). Assim, uma firma pode ganhar vantagem competitiva através da implantação de estratégias de criação de valor que não sejam facilmente duplicadas pelas firmas concorrentes. 
O gerenciamento da cadeia de suprimentos introduz um novo foco da VBR, analisando as atividades ao longo da cadeia individualmente e coletivamente, a fim de verificar se essas atividades criam recursos para a empresa focal (HITT; XU; CARNES, 2016). Para isso, é preciso que as empresas conheçam os elementos da sua cadeia de valor, de modo que elas possam explorar esses elementos apropriadamente para ser fonte de vantagem competitiva. Considerando que as relações são recursos intangíveis e fontes de vantagens competitivas em cadeia de suprimentos (CAO; ZHANG, 2011), a visão relacional (VR) surge como um importante conceito para entender e analisar a vantagem competitiva em rede, por meio de contribuições idiossincráticas conjuntas entre parceiros de uma cadeia (DYER; SINGH, 1998).

Um desafio fundamental na pesquisa acerca da RBV é a identificação de recursos e capacidades estratégicas em sua cadeia. Nesse contexto, Hitt (2016) afirma que a VBR pode ser útil para identificar e destacar como as atividades da cadeia de suprimentos pode ser gerenciada para contribuir para a vantagem competitiva de uma empresa. Em sua pesquisa, ele concluiu que a VBR tem sido ampliada de forma a incorporar recursos externos, especialmente com foco em gestão da cadeia de suprimentos e, consequentemente, cadeia de valor. Isso também é evidenciado por Dyer e Singh (1998), que afirmam que empresas que combinam recursos de maneiras únicas podem obter uma vantagem sobre empresas concorrentes que não estão dispostas a fazê-lo. Assim, as ligações entre as firmas podem ser uma fonte de rendas relacionais e vantagem competitiva.

Quando se analisa a literatura, verifica-se o interesse de alguns pesquisadores sobre a temática, como pode ser observado na pesquisa desenvolvida por De Martino et al. (2015) que analisou a criação de valor nas redes de relacionamentos de um porto por meio de dois conceitos principais: alocação e interação de recursos. Além disso, trabalhos como o de Gretzinger e Royer (2014) e Fawcett et al. (2015) enfatizam a importância de uma análise relacional em empresas que atuam em distintos arranjos interorganizacionais como fonte de vantagem competitiva.

Dessa forma, esse artigo pretende responder à seguinte questão: como as atividades e recursos do processo de importação de uma carga conteinerizada permitem o desenvolvimento de vantagens colaborativas (e, consequentemente, agregação de valor)? A pesquisa utilizará como suporte teórico aspectos da Cadeia de Valor, VBR e a VR. Para tanto, Revista Eletrônica de Estratégia \& Negócios, Florianópolis, v.12, n. 3, set./dez. 2019. 
foi selecionado um elo do processo de importação de uma carga conteinerizada proveniente da China para o Brasil, sendo analisada a ótica da empresa F3 Import Export, que atua como trading. $\quad$ O desenvolvimento desse artigo é importante, uma vez que contribui para a literatura abordando uma temática recente por meio de uma revisão teórica e uma aplicação prática no setor do comércio marítimo (LEWIS; SLACK; HOWARD, 2010). Dessa forma, este trabalho contribui na expansão do foco da empresa individual para redes entre organizações, como análise da interação da cadeia e dos recursos compartilhados por essa rede (BARALDI; GRESSETVOLD; HARRISON, 2012).

O restante deste artigo está estruturado da seguinte forma. Após esta introdução é apresentado um aporte teórico acerca dos temas predominantes do trabalho: cadeia de valor, visão relacional (VR) e visão baseada em recursos (VBR). Em seguida, é detalhada a metodologia da pesquisa para a realização da empírica realizada. Posteriormente, os resultados são descritos e discutidos. Por fim, apresentam-se as conclusões, contribuiç̧̃̃es, limitações e sugestões de novas pesquisas.

\section{CADEIA DE VALOR}

A estratégia de uma empresa define o comportamento de suas atividades. A partir dessa premissa, surgiu o conceito de Cadeia de Valor, que tem o objetivo de analisar a consistência interna das atividades de uma empresa. As atividades são os pilares da construção de vantagens competitivas, sendo consumidoras de recursos, por um lado, e criadoras de valor por outro (PORTER, 1991).

Para Kotler (2000), criar valor para o cliente pode ser definido como a diferença entre o valor e o custo gerado para o cliente. Dessa forma, criação de valor é representado pelo conjunto de vantagens que o cliente deseja ao se obter um produto e o conjunto de custos que o produto inclui (JARDIM et al., 2015).

Assim, um conjunto de desempenhos empresariais que adicionam valor aos produtos da organização é denominado cadeia de valor. Criar valor é um importante componente para uma empresa ganhar vantagem competitiva e fazer melhor suas escolhas estratégicas. 
A cadeia de valor é composta por atividades principais e atividades de apoio, conforme apresentado na Figura 1. As atividades principais (ou primárias) se referem a atividades envolvidas na criação física do produto, seu processo de venda, distribuição e pós-venda. Já as atividades de apoio são aquelas atividades que dão apoio às atividades principais e a elas mesmas.

Figura 1 - Cadeia de Valor

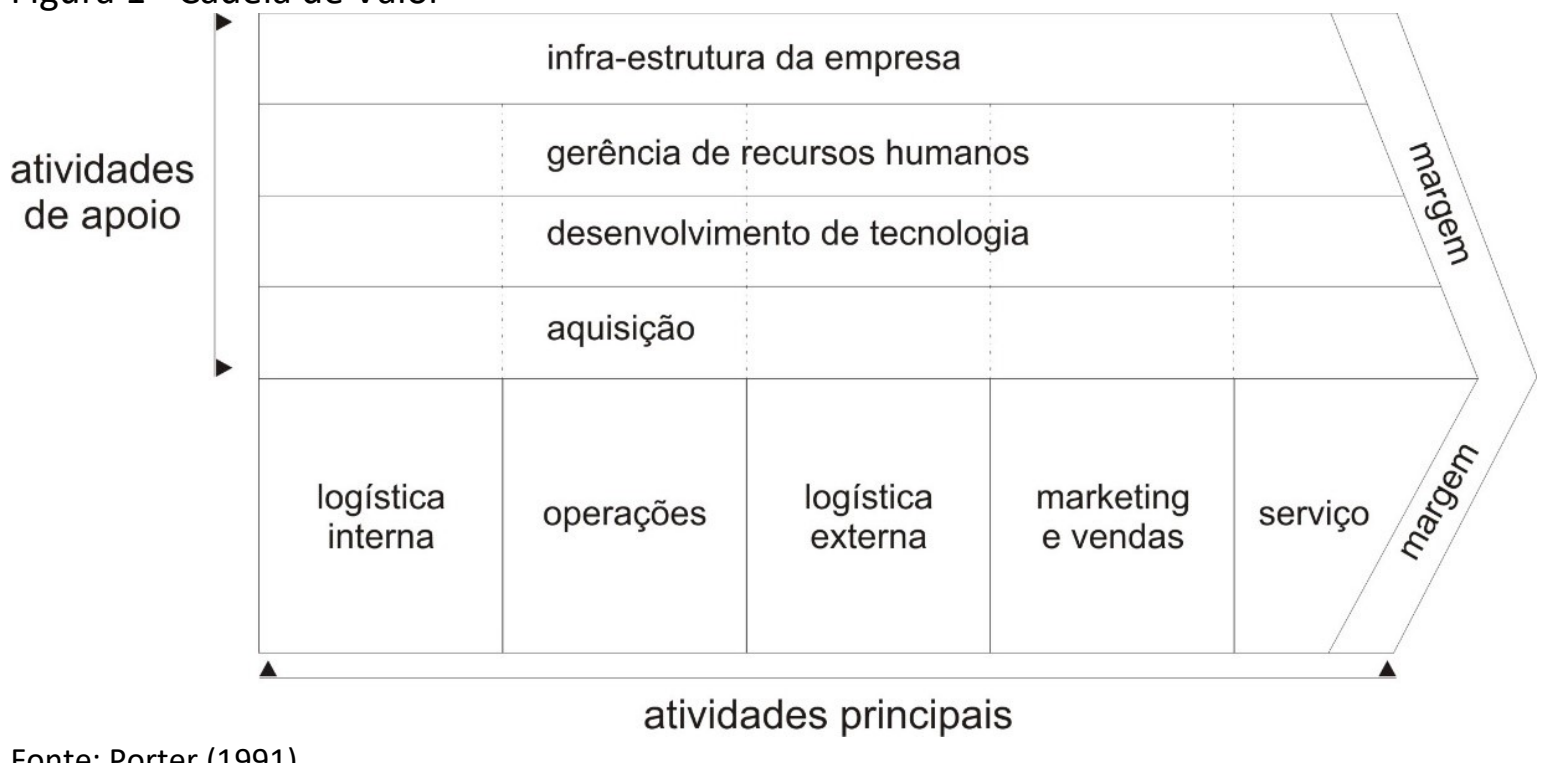

Novaes (2001) afirma que o valor de um produto é composto pela margem e pelas atividades de valor dele. E que, portanto, a cadeia de valor não é um conjunto de atividades independentes, e sim, um sistema de atividades interdependentes.

Ao se analisar a cadeia de valor de um produto, uma empresa pode executar apenas algumas atividades da sua cadeia completa, enquanto outras atividades serão executadas em outras organizações com as quais se relacionam (MARCIANO et al., 2010). De modo que várias empresas podem compartilhar as atividades de valor de um determinado produto e cada uma delas participa do processo de criação de valor.

Assim, a cadeia de valor de um produto é composta a partir da identificação das atividades que agregam valor ao produto, confrontando o modelo genérico proposto por Porter. Desse modo, deve-se verificar quais empresas executam as atividades de valor de um produto, bem como os objetivos estratégicos que nortearam a ligação entre essas empresas (MARCIANO et al., 2010). 
Portanto, para se mapear a cadeia de valor um produto, deve-se identificar as atividades de valor que fazem parte do seu processo produtivo, passando pela aquisição de matéria-prima e até a entrega do seu produto final ao cliente.

\section{VISÃO RELACIONAL (VR) E VISÃO BASEADA EM RECURSOS (VBR) NO CONTEXTO DE CADEIAS DE VALOR}

O conceito básico da VBR advém de que com a posse e controle de recursos que criam valor são únicos, é possível ganhar vantagem competitiva, de modo que os ativos tangíveis e intangíveis são os principais indutores e fontes de criação de valor (RODRIGUES; ALCANTARA, 2015).

Os recursos de uma empresa incluem todos os ativos, capacitações, processos organizacionais, atributos da empresa, informações, conhecimentos, entre outros, que a permitam conceber e implementar suas estratégias para criação de valor e que melhorem a eficiência e eficácia da empresa (BARNEY, 1991). Segundo Porter (1991), a fonte de vantagem competitiva de uma empresa se encontra primariamente nos recursos de competências desenvolvidas e controladas por essa empresa.

Barney (1991) afirma que uma firma precisa de recursos valiosos e raros de forma a ganhar vantagem competitiva, porém, para manter essa vantagem competitiva ao longo do tempo, esses recursos precisam ser difíceis de imitar e não substituíveis por outros recursos de outras firmas. As empresas que são capazes de acumular recursos e capacidades, que são raros, valiosos, não substituíveis e difíceis de imitar, alcançarão uma vantagem competitiva sobre as empresas concorrentes. Tais aspectos dão origem ao modelo (VRIN) e a empresa deve estar organizada (0) para explorar o potencial desses recursos. Os detalhes destes recursos podem ser verificados no Quadro 1.

Quadro 1 - Recursos VRIO

\begin{tabular}{|l|l|}
\hline Recursos & \multicolumn{1}{c|}{ Propriedades } \\
\hline Valiosos & $\begin{array}{l}\text { Os recursos são valiosos quando permitem a empresa implementar estratégias } \\
\text { que aumentem sua eficiência e efetividade. }\end{array}$ \\
\hline
\end{tabular}




\begin{tabular}{|c|l|}
\hline Recursos & \multicolumn{1}{|c|}{ Propriedades } \\
\hline Raros & $\begin{array}{l}\text { Os recursos são raros e apresentam vantagem competitiva quando uma } \\
\text { estratégia de criação de valor implantada por uma empresa não é } \\
\text { simultaneamente implementada por qualquer concorrente atual ou potencial. }\end{array}$ \\
\hline Inimitáveis & $\begin{array}{l}\text { Além de outras empresas não possuírem os recursos, eles devem ser difíceis de } \\
\text { ser conseguidos ou imitados pelos concorrentes. }\end{array}$ \\
\hline Não Substituíveis & $\begin{array}{l}\text { Para obter vantagem competitiva, os recursos também não podem ser } \\
\text { considerados substituíveis por recursos equivalentes, pois, caso contrário, } \\
\text { concorrentes poderiam implementar a mesma estratégia, usando recursos } \\
\text { distintos. }\end{array}$ \\
\hline Organização & $\begin{array}{l}\text { Para que se possa aproveitar o máximo de seus recursos, a empresa deve } \\
\text { organizá-los e explorá-los. Não basta que a empresa tenha recursos valiosos, } \\
\text { raros, inimitáveis e não substituíveis, a firma precisa explorar o potencial desses } \\
\text { recursos em conjunto com a estratégia da empresa para gerar vantagens } \\
\text { competitivas sustentáveis. }\end{array}$ \\
\hline
\end{tabular}

Fonte: Adaptado de Barney (1991) e Gohr (2011)

Barney (1991) ainda classifica os recursos em três tipos de categorias:

1. Recursos físicos: equipamentos, terras, recursos naturais e matérias-primas;

2. Recursos humanos: trabalhadores produtivos, técnicos e gerenciais;

3. Recursos organizacionais: formado pelas rotinas que coordenam os recursos humanos e físicos de maneira produtiva.

Os recursos ora citados também podem ser tangíveis, os quais podem ser observados e avaliados com clareza, como recursos físicos; e, intangíveis, que não podem ser diretamente observados ou quantificados, como a reputação de uma empresa ou produto, cultura organizacional, habilidades de gerenciamento e coordenação e conhecimentos, entre outros (WILK; FENSTERSEIFER, 2003).

Os desafios mais importantes associados aos recursos e capacidades de uma empresa são identificá-los, desenvolvê-los, protegê-los, implantá-los e alavancá-los (FEIZ ABADI; CORDON, 2012). Assim, os executivos precisam gerenciar seus recursos para desenvolver capacidades que permitam a empresa adquirir vantagem competitiva.

A VBR tradicional avalia os recursos das firmas enquanto entidades autônomas. Porém, os recursos estratégicos críticos podem extrapolar os limites da firma, resultando em rendas 
relacionais (RODRIGUES; ALCANTARA, 2015). A partir dessa premissa, surge o conceito da VBR estendida (VBRE), que tem como principal foco o fato de que os recursos estratégicos são oriundos não apenas dentro dos limites das organizações, mas também fora (LAVIE, 2006), conforme também preconiza a visão relacional. Essa teoria parte do pressuposto de que as rendas relacionais são possíveis quando parceiros de aliança combinam, trocam ou investem em conhecimento e recursos e empregam mecanismos de governança eficazes que reduzem os custos de transação ou permitem a realização de rendas por meio da combinação sinérgica de ativos, conhecimento ou capacidades (DYER; SINGH, 1998).

O Quadro 2, a seguir, detalha as diferenças entre a Visão Baseada em Recursos e a Visão Relacional.

Quadro 2 - Comparação entre VBR e VR

\begin{tabular}{|c|c|c|}
\hline Dimensões & Visão Baseada em Recursos & Visão Relacional \\
\hline Unidade de Análise & Firma & Par ou rede de firmas \\
\hline $\begin{array}{l}\text { Fontes primárias de } \\
\text { retornos de lucros }\end{array}$ & $\begin{array}{c}\text { Recursos físicos escassos (terra, } \\
\text { insumos) } \\
\text { Recursos humanos / know-how } \\
\text { (talento gerencial) } \\
\text { Recursos tecnológicos (tecnologia } \\
\text { de processo) } \\
\text { Recursos financeiros } \\
\text { Recursos intangíveis (reputação) }\end{array}$ & $\begin{array}{l}\text { Investimentos específicos de } \\
\text { relacionamento } \\
\text { Rotinas de compartilhamento de } \\
\text { conhecimento entre firmas } \\
\text { Dotações complementares de recursos } \\
\text { Governança eficaz }\end{array}$ \\
\hline $\begin{array}{l}\text { Mecanismos que } \\
\text { preservam os lucros }\end{array}$ & $\begin{array}{c}\text { Barreiras de imitação (firma): } \\
\text { Escassez de recursos } \\
\text { Ambiguidade causal } \\
\text { Deseconomias de compressão de } \\
\text { tempo } \\
\text { Interconexão de estoques de } \\
\text { ativos }\end{array}$ & $\begin{array}{c}\text { Barreiras de imitação (rede): } \\
\text { Ambiguidade causal } \\
\text { Deseconomias de compressão de tempo } \\
\text { Interconexão de estoques de ativos } \\
\text { interorganizacionais } \\
\text { Escassez de parceiros } \\
\text { Indivisibilidade de recursos } \\
\text { Ambiente institucional }\end{array}$ \\
\hline Propriedade & Firma individual & Coletivo (parceiros comerciais) \\
\hline
\end{tabular}

Fonte: Adaptado Dyer e Singh (1998).

Nesse sentido, a VR e a VBR fornecem um meio único de analisar a cadeia de suprimentos para examinar as atividades ao longo da cadeia de valor, individual e coletivamente. Cada atividade ao longo da cadeia requer recursos particulares e capacidades para realizar a tarefa e contribuir para uma vantagem competitiva. No entanto, é importante 
integrar as capacidades existentes em toda a cadeia e aproveitá-las de maneira eficaz, a fim de criar uma vantagem competitiva (HITT; XU; CARNES, 2016).

Recursos relacionais são recursos externos incorporados na rede de alianças da empresa, que apresentam oportunidades estratégicas e afetam o valor da empresa (LAVIE, 2006). Quando as empresas conseguem gerar rendas competitivas, elas tendem a adquirir um benefício associado à colaboração, como aprendizado, baixos custos transacionais e agrupamento de recursos (DYER; SINGH, 1998).

Dyer e Singh (1998) formularam quatro características que definem as fontes de rendas relacionais que geram vantagem competitiva, as quais estão demonstradas no quadro 3 , a seguir.

Quadro 3 - Fontes de Rendas Relacionais

\begin{tabular}{|c|c|}
\hline Fontes & Conceitos \\
\hline $\begin{array}{c}\text { Investimento em ativos específicos à } \\
\text { relação }\end{array}$ & São investimentos em ativos/recursos especializados em conjunto com \\
parceiros de uma aliança.
\end{tabular}

Fonte: Elaboração dos autores, baseado em Dyer e Singh (1998).

Assim, muitos recursos estratégicos e as capacidades de uma empresa não estão limitados às fronteiras da empresa, estendendo também a sua rede. Todas as características únicas não residem apenas dentro dos limites de uma empresa, existem alguns recursos além desses limites. Portanto, para Feiz Abadi e Cordon (2012), a teoria e atenção empírica de uma pesquisa devem ser direcionadas ao nível do recurso, não ao nível da empresa. Na sequência, é apresentado uma breve relação entre recursos e capacidades com cadeia de valor.

Porter (1985) argumenta que as empresas que otimizam suas atividades de cadeia de valor em comparação com a concorrência têm uma chance melhor de alavancar recursos valiosos em vantagem competitiva sustentável. Com isso, conhecer os recursos e capacidades dessa cadeia se torna um item necessário para atingir essa vantagem competitiva. 
Em seu estudo, Prajogo, Mcdermott e Goh (2008) alinharam a cadeia de valor e VBR, por meio de uma análise de como os elementos críticos de uma cadeia de valor impacta na qualidade e inovação de um produto. Para isso, eles aplicaram um Survey e concluíram que as empresas que conhecem quais elementos específicos de sua cadeia de valor estão associados a métricas de desempenho específicas e exploram esses elementos apropriadamente têm o potencial mais forte de produzir superioridade competitiva.

Nesse contexto, uma empresa deve buscar ter uma comunicação eficaz e valores colaborativos compartilhados com os parceiros da cadeia de suprimentos. Com isso, a empresa aumenta sua competência relacional e colaborativa, servindo como uma capacidade chave para fornecer vantagem competitiva (PRIEM; SWINK, 2012).

Para examinar essas relações entre os aspectos externos da cadeia de suprimentos, os processos internos e o desempenho, fez-se uma análise da cadeia de valor por meio da visão relacional, combinando esses aspectos que são considerados estratégicos (PRAJOGO; OKE; OLHAGER, 2016).

\section{METODOLOGIA}

Para desenvolvimento desta pesquisa, foi utilizado o método de estudo de caso. De acordo com Yin (2001), um estudo de caso é definido como uma pesquisa empírica acerca de um fenômeno contemporâneo dentro de um contexto de uma situação real. Assim, um estudo de caso é um procedimento que representa uma maneira de se investigar um tópico empírico através de um conjunto de metodologias pré-especificadas, justificando esse método como melhor escolha para a presente pesquisa.

Inicialmente, procedeu-se um estudo literário acerca dos temas abordados na pesquisa, tais como: cadeia de valor, VR e VBR e uma junção entre recursos e capacidades com cadeia de valor. Em seguida, foi feito um mapeamento da cadeia da importação de um material em contêiner, no caso o granito, através de entrevistas informais com membros da cadeia. Posteriormente, foi necessário escolher um elo da cadeia a ser analisado pela ótica da Cadeia de Valor com aporte teórico da VBR deste elo. 
Nesse contexto, o uso de entrevistas semiestruturadas teve a intenção de se obter informações de natureza profissional do caso estudado. Para esta pesquisa, as entrevistas foram feitas informalmente, de modo a deixar o entrevistado à vontade e contribuir ao máximo para a pesquisa. O Quadro 4 representa o modelo de análise que auxiliou no desenvolvimento da pesquisa empírica, a fim de se alcançar os objetivos definidos.

Quadro 4 - Modelo de Pesquisa para Análise da Cadeia, Atividades e Recursos

\begin{tabular}{|c|c|c|c|}
\hline Etapa & Natureza de Análise & Instrumento de Pesquisa & $\begin{array}{l}\text { Fonte Para Formulação de } \\
\text { Roteiro de Entrevista }\end{array}$ \\
\hline $\begin{array}{l}\text { Mapear a Cadeia } \\
\text { do Processo } \\
\text { Estudado }\end{array}$ & $\begin{array}{l}\text { Cadeia de Suprimentos } \\
\text { Fluxo de Processo }\end{array}$ & Entrevista e Observação Direta & (SANTOS, 2014) \\
\hline $\begin{array}{c}\text { Definir Elo a Ser } \\
\text { Estudado }\end{array}$ & Análise de Elo Crítico & Observação Direta & - \\
\hline $\begin{array}{l}\text { Identificar } \\
\text { Atividades da } \\
\text { Cadeia de Valor }\end{array}$ & Primárias e de Apoio & Entrevista e Observação Direta & (PORTER, 1991) \\
\hline $\begin{array}{c}\text { Identificar e } \\
\text { Avaliar os Recursos } \\
\text { e Atividades } \\
\text { Geradoras de } \\
\text { Vantagem } \\
\text { Competitiva } \\
\end{array}$ & $\begin{array}{l}\text { Recursos Tangíveis e } \\
\text { Intangíveis }\end{array}$ & $\begin{array}{l}\text { Entrevista com a adoção de escala } \\
\text { Likert de } 5 \text { pontos para identificar } \\
\text { os recursos mais importantes }\end{array}$ & (SILVA; GOHR; LEITE, 2018) \\
\hline $\begin{array}{l}\text { Analisar Vantagem } \\
\text { Colaborativa }\end{array}$ & $\begin{array}{l}\text { Fontes de Rendas } \\
\text { Relacionais }\end{array}$ & $\begin{array}{l}\text { Entrevista e Análise do Conteúdo } \\
\text { das Informações }\end{array}$ & (FAUSTINO; GOHR, 2016) \\
\hline
\end{tabular}

Fonte: Elaborado pelos autores (2019).

A pesquisa de campo foi realizada no mês de agosto de 2018, sendo a entrevista semiestruturada aplicada de forma de presencial com gravação, totalizando duas visitas de 120 minutos cada. As análises foram feitas a partir dos obtidos, sob a ótica das teorias apresentadas.

A empresa foco de investigação é uma empresa trading, com sede em João Pessoa PB, chamada F3 Import Export. A seleção dessa empresa se justifica uma vez que ela é responsável pelo gerenciamento de todo o processo de importação, sendo uma empresa essencial nesse processo. Além da Trading, foi selecionado o elo dessa empresa com uma empresa importadora no Brasil. Essa escolha se justificou pela relação de alta interação, confiança e longo prazo entre as duas empresas. A empresa importadora é uma cliente da 
trading desde a sua fundação em 2015. A Trading faz a ligação entre o importador e o exportador. Esse agente é responsável por negociar a mercadoria e gerenciar sua aquisição desde a saída da fábrica na China até a chegada na empresa importadora. Convém destacar que a análise foi feita considerando a ótica da trading.

A empresa foco, fundada em 2015, possui sede na cidade de João Pessoa - PB, atua como trade no comércio internacional, além de oferecer serviços como: intermédio de processos de importação e exportação, gestão da logística, planejamento tributário da operação e consultorias na área. Além da sede, a empresa conta com suporte de escritórios na China, Emirado Árabes, Estados Unidos e Argentina.

\section{RESULTADOS E DISCUSSÕES}

Esta seção está organizada da seguinte forma: descrição da cadeia do processo de importação da carga estudada; seguida pela análise da cadeia de valor (atividades) e recursos da empresa foco (trading) e, por último; a análise da relação, com base na VR, entre a empresa trading e a empresa importadora.

\subsection{PROCESSO DE IMPORTAÇÃO DE UMA CARGA CONTEINERIZADA}

De acordo com Keedi (2012), a importação corresponde à aquisição ou troca de uma mercadoria que seja de interesse da organização ou empresa importadora e representa a entrada de bens fabricados no exterior. Para a realização desse processo, devido à dificuldade de gerenciamento e documentação, algumas empresas importadoras contratam uma empresa trading especializada para atuar e representá-la.

No estudo de caso, o processo de importação dessa carga conteinerizada começa com a requisição da empresa importadora aqui no Brasil, que contrata a empresa trading para intermediar e ser responsável pela aquisição e gestão logística da mercadoria.

A trading, então, faz uma pesquisa e homologação de fornecedores disponíveis para a carga em questão, bem como um estudo tributário e apresenta um orçamento ao cliente. Com o orçamento aprovado, a empresa trading entra em contato com o fornecedor do exterior para dar início à produção. Para o caso em estudo, a empresa exportadora tem atuação na 
China. Sendo contactada, a empresa exportadora dá início ao processo de produção da carga, para então exportá-la através de um Porto Chinês.

Esse processo realizado na China é acompanhado por um agente de cargas local, também contratado pela empresa trading que fica responsável por receber a mercadoria no Porto Chinês e garantir a chegada dele no Porto Nordestino do Brasil.

Ao chegar no Porto Nordestino, a carga passa a ser armazenada em um armazém alfandegário, contratado também pela trading. Assim, dá-se início ao processo de documentação para liberação da carga. Essa documentação é feita junto à Receita Federal, para nacionalização da carga.

Com a liberação adquirida junto à Receita Federal, uma empresa transportadora nacional fica responsável por transportar a carga via rodovias, do porto até a empresa importadora. Com a chegada da carga, a empresa trading realiza um contato de pós-venda com a empresa importadora, e assim, o processo é finalizado. O resumo dessa cadeia pode ser observado na Figura 2.

O elo que será foco deste estudo está destacado em vermelho. O elo é entre a empresa trading e uma empresa cliente, que é a empresa importadora. Esse elo foi escolhido devido a relação de confiança existente entre as duas empresas observadas durante a entrevista. A empresa trading tem como cliente essa empresa importadora desde o ano de fundação (2015) até o presente momento.

Figura 2- Fluxo do Processo de Importação de uma Carga Conteinerizada 


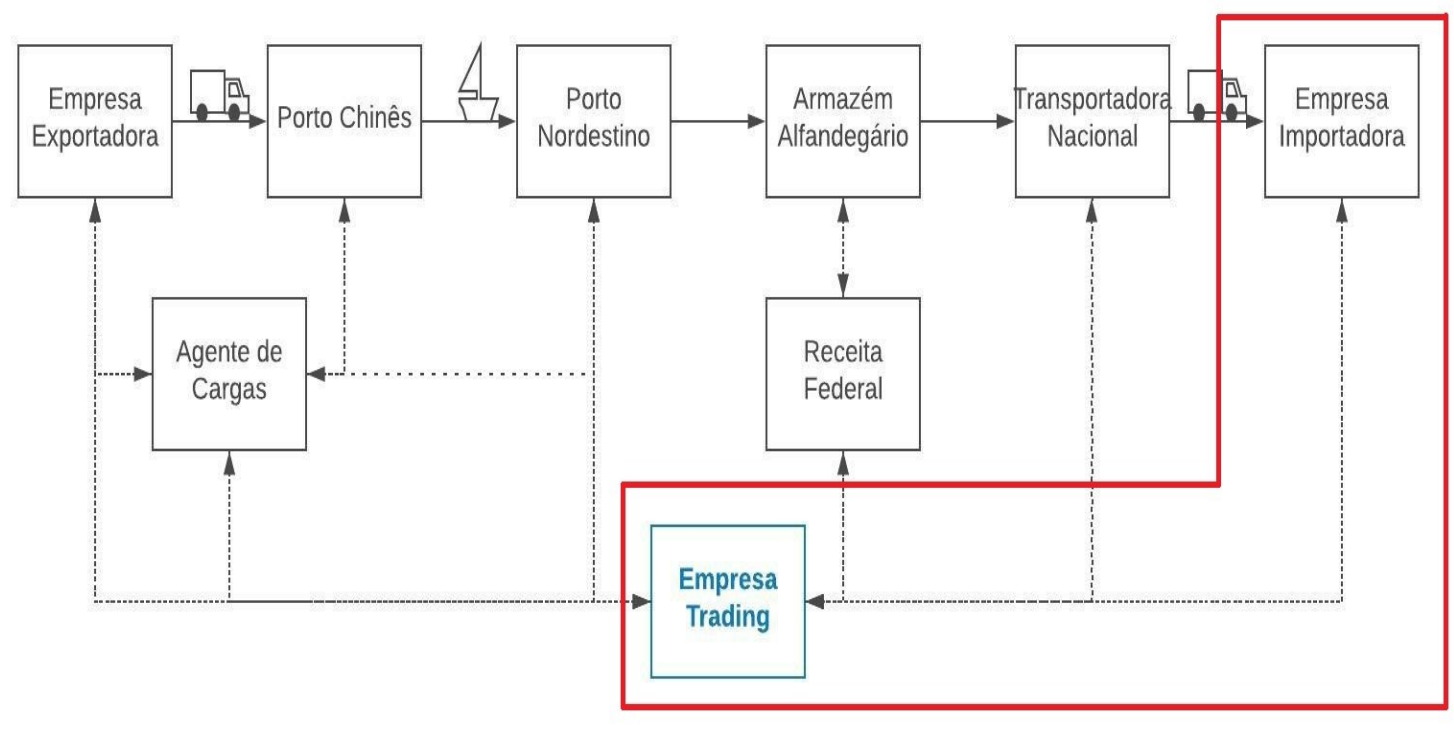

Fonte: Elaborado pelos autores (2019).

O material flui a partir da empresa exportadora, que entrega a carga no Porto Chinês, intermediado por um agente de cargas. Esse agente é responsável pelo recebimento e acompanhamento do transporte marítimo da carga até o Porto Nordestino. Lá, ele fica alguns dias em espera no armazém alfandegário até conseguir a liberação pela Receita Federal. Com a liberação e através de uma transportadora, a carga é levada via rodovia até a empresa importadora. Todo esse processo é gerenciado pela empresa trading que possui relação com todos esses agentes, demonstrado pelas linhas de fluxo de informação.

Todo esse processo leva em torno de 90 dias, desde a produção da carga pela empresa exportadora na China até a chegada dela na empresa importadora no Brasil.

\subsection{DESCRIÇÃO DA CADEIA DE VALOR E RECURSOS}

De acordo com Porter (1991), é possível mapear a cadeia de valor da empresa trading com foco na importação de uma carga conteinerizada e identificar as atividades primárias e de apoio. Foram feitas algumas alterações em relação à cadeia genérica, dentre elas a exclusão da atividade primária de logística interna, visto que essa atividade não se aplica à empresa foco. Como a empresa oferece um serviço, ela não possui logística interna de materiais. Além disso, a atividade de gestão de recursos humanos da cadeia genérica está aqui destacada como Gestão de Mão de Obra e Consultorias. A cadeia de valor da empresa trading para o processo de importação dessa carga está detalhada na Figura 3. 
Figura 3 - Cadeia de Valor: Empresa Trading

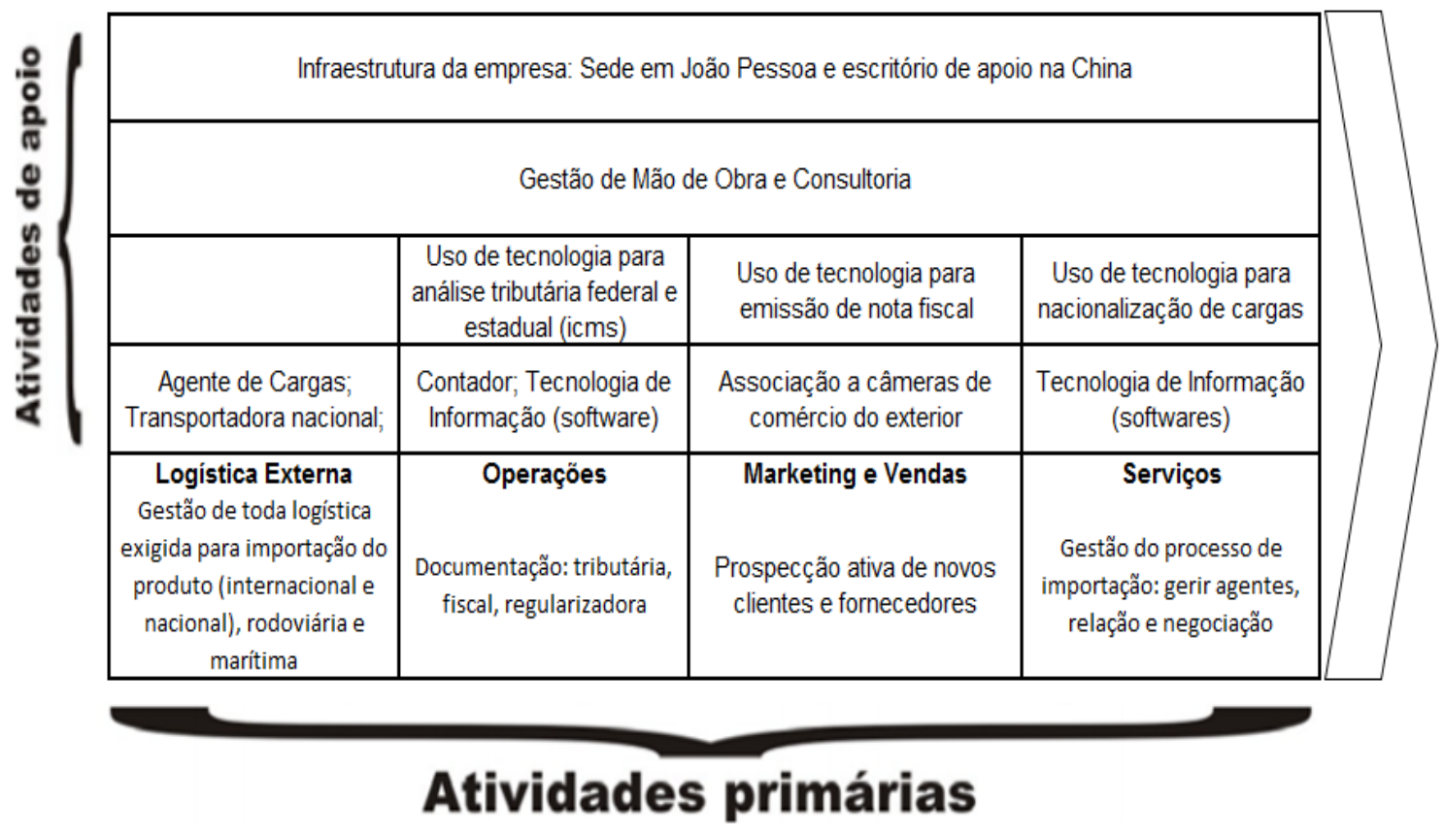

Fonte: Elaborado pelos autores (2019).

Analisando a cadeia de valor da empresa, observam-se as atividades de apoio em relação a cada atividade primária. É possível notar que a tecnologia é um apoio essencial para a maioria das atividades, visto que a empresa faz uso de softwares para auxiliar suas operações, serviços e gestão. A empresa não possui uma política de Recursos Humanos, já que só possui cinco funcionários. Porém, ela gerencia mão de obra terceirizada e faz uso de consultorias quando necessário. Além disso, a empresa possui como principais aquisições a contratação do agente de cargas que gerencia a carga na China e a transportadora nacional que transporta a carga do Porto Nordestino até o cliente. A atividade primária de logística externa não possui apoio de desenvolvimento de tecnologia, estando esse quadrado em branco para essa atividade.

Por meio da Cadeia de Valor já podem ser observados recursos dentro das atividades de apoio que contribuem para vantagem competitiva. Assim, foi possível encontrar os principais recursos (tangíveis e intangíveis) da empresa trading e sua importância para a vantagem competitiva, sob a ótica da VBR, e relacioná-los com as atividades primárias da cadeia de valor, conforme observado pelo Quadro 5. 
Quadro 5 - Recursos Identificados

\begin{tabular}{|c|c|c|c|}
\hline Recurso & Categoria & $\begin{array}{c}\text { Atribuição a } \\
\text { Vantagem } \\
\text { Competitiva }\end{array}$ & $\begin{array}{c}\text { Relação com Atividade Primária } \\
\text { (Cadeia de Valor) }\end{array}$ \\
\hline $\begin{array}{c}\text { Infraestrutura - Sede em João } \\
\text { Pessoa e escritório de apoio na } \\
\text { China }\end{array}$ & Tangível & 5 & Operações e Serviços \\
\hline Equipamentos: Computadores & Tangível & 4 & Todas \\
\hline Pessoal: Funcionários e gestores & Tangível & 5 & Todas \\
\hline $\begin{array}{c}\text { Infraestrutura Regional: Rodovias e } \\
\text { Portos }\end{array}$ & Tangível & 2 & Logística Externa \\
\hline Localização da empresa (Nordeste) & Intangível & 3 & Serviços \\
\hline Experiência nas Operações & Intangível & 5 & Todas \\
\hline $\begin{array}{c}\text { Relacionamentica Externa, Operações e } \\
\text { (Cliente, Fornecedor, Órgãos e } \\
\text { Governo) }\end{array}$ & Intangível & 5 & $\begin{array}{c}\text { Logística Externa, Operações e } \\
\text { Serviços }\end{array}$ \\
\hline Reputação da Empresa & Intangível & 5 & Marketing e Vendas \\
\hline Eficiência Operacional & Intangível & 5 & 5 \\
\hline
\end{tabular}

Fonte: Elaborado pelos autores (2019).

Pelo Quadro 5, é possível observar que os recursos intangíveis são os que mais se destacam. Isso se deve ao fato de que a empresa é uma prestadora de serviço e tem como principal diferencial sua experiência, relacionamentos, reputação e eficiência operacional. Essa eficiência operacional inclui softwares e consultorias utilizados pela empresa. Os relacionamentos abrangem os clientes e fornecedores, além das relações com câmeras de comércio exterior e governos que contribuem com incentivo fiscal. Os recursos tangíveis que mais se destacam são: (i) a infraestrutura, que apresenta como um diferencial a presença de escritório de apoio no lugar em que a mercadoria é produzida (China); e, (ii) as pessoas, que abrangem os funcionários responsáveis por executar, manter e gerenciar as operações.

Além disso, pode-se observar a relação dos recursos com as atividades primárias da cadeia de valor encontradas para esse processo. Tem-se, por exemplo, que o recurso de infraestrutura da empresa contribui para execução das atividades primárias de Operações (documentação) e Serviços (Gestão do Processo de Importação).

Os recursos que obtiveram notas igual ou menor a 3 não apresentam grande diferencial em relação à vantagem competitiva da empresa. 


\subsubsection{Descrição das fontes de rendas relacionais}

Conforme mencionado anteriormente, a Visão Relacional (VR) (DYER; SINGH, 1998) aponta quatro fatores que são considerados fontes de rendas relacionais: investimento em ativos específicos à relação, troca de conhecimentos, dotação de recursos complementares e mecanismos de governança. Esses quatro fatores são analisados a seguir de acordo com os dados coletados.

\subsubsection{Investimentos em ativos específicos à relação}

Foi observado que a empresa foco (trading) possui investimentos em ativos específicos em conjunto com a empresa parceira em relação a ativos humanos. Ela faz a gestão financeira de todo o processo pago pela empresa importadora e, com isso, são realizados investimentos em contratação de prestadores de serviços e parceiros, como o agente de carga que atua na China, o armazém alfandegário que a carga fica armazenada e também a empresa de distribuição que leva o produto do armazém até a empresa importadora. Esses investimentos são realizados sob o nome da empresa trading, a qual é uma representante da empresa importadora. Eles contribuem para gerar garantias ao cliente de que ele receberá o produto com o menor custo e tempo possível.

Outro aspecto observado, foi que a empresa trading ocasionalmente começa a desembolsar o dinheiro para os trâmites da importação antes mesmo de receber da empresa importadora, baseada na forte relação de confiança de que o cliente irá cumprir o contrato. Essa prática não é comum na empresa trading, mas acontece nesse caso específico, devido à forte relação com o cliente. A empresa importadora em questão possui relação com trading desde a sua fundação.

\subsubsection{Troca de conhecimentos}

As duas empresas possuem compartilhamento de informações, como o acesso mútuo ao Sistema de Comércio Exterior (SISCOMEX) da Receita Federal, no qual a trading atua como representante do cliente. Existem também compartilhamentos acerca de tributos e custos durante todo o processo, bem como um follow-up semanal do andamento do processo da carga repassado pela trading ao cliente. 
Além disso, as empresas participam de encontros informais frequentes com as duas diretorias, desde feiras internacionais de comércio exterior até cafés e almoços.

\subsubsection{Dotação de recursos complementares}

As empresas possuem recursos que se complementam. Para o caso específico desta pesquisa, a empresa importadora possui um know-how acerca do produto específico que está sendo importado, como as suas características de manuseio e armazenamento e sua forma de embalagem. Já a trading é especialista no processo de importação, conforme demonstrado na sua cadeia de valor, como a gestão do processo de importação, englobando os agentes, a logística e a documentação. Assim, esses conhecimentos (recursos intangíveis) são compartilhados e complementados para que o processo de importação ocorra com eficiência.

Ademais, as empresas realizam novos projetos em conjunto de novas cargas para importação. A empresa importadora interage com o conhecimento sobre o novo produto que deseja e a trading analisa a viabilidade de se importar esse outro produto, gerando novas parcerias.

\subsubsection{Mecanismos de governança}

O elo de aliança estudado possui como governança efetiva um contrato formal para todo o serviço ofertado. Normalmente em processos desses tipos, a empresa trading esconde o nome da empresa exportadora e da empresa importadora um do outro nos contratos. Porém, nesse elo específico, isso não ocorre, devido ao alto grau de confiança e parceria na relação.

No contrato existem cláusulas de confidencialidade de informações e de exclusividade. As práticas e conhecimentos de ambas empresas não podem ser repassadas a terceiros e as duas empresas são exclusivas uma da outra no processo de importação desse produto específico. Nem a trading pode importar esse produto para outra empresa e nem a empresa importadora pode importar esse produto através de outra empresa trading.

Além do contrato, existem alguns casos em que a confiança rege o relacionamento, como a antecipação de pagamentos pela trading antes de recebê-lo do cliente. Alguns órgãos 
norteiam o processo, como a Receita Federal do Brasil, o Ministério do Desenvolvimento da Indústria e do Comércio e o Ministério da Agricultura, Pecuária e Abastecimento.

\subsection{DISCUSSÃO}

De acordo com o que foi apresentado, pode-se analisar algumas questões acerca de cadeia de valor e recursos da empresa trading com as fontes de vantagem colaborativa entre o elo estudado.

Sob a ótica de uma empresa trading, foi encontrado que sua cadeia de valor abrange como atividades primárias a logística externa (gestão da carga importada), operações (documentação), marketing e vendas (prospeç̧ão de novos clientes e fornecedores) e serviços (gestão dos agentes do processo de importação). Para desenvolver essas atividades com competência, foram identificados os principais recursos, sob a ótica da VBR, que contribuem para geração de vantagem competitiva. Entre esses recursos, destacam-se os recursos tangíveis como infraestrutura da empresa (sede na Paraíba e escritório de apoio na China) e seus funcionários e gestores. E também os recursos intangíveis como a experiência nas operações, o relacionamento com stakeholders, a reputação da empresa e a eficiência operacional da empresa.

Acerca das fontes de rendas relacionais, foi observado uma forte relação entre os elos, o que contribui para uma geração de vantagem colaborativa. Foi verificado que as empresas possuem um relacionamento forte e de confiança. Todas as quatros fontes de rendas relacionais aparecem na aliança entre as duas empresas contribuindo para a criação de valor conjunto e, consequentemente, para o desenvolvimento de vantagens colaborativas.

Entre as fontes geradas, destacam-se os investimentos em prestadores de serviços de forma conjunta (investimentos em ativos específicos), compartilhamento sobre custos, tributos e fluxo da carga semanal (troca de conhecimentos), a complementaridade entre os conhecimentos de ambas as empresas acerca do produto e do processo de importação (dotação de recursos complementares) e uma governança regida de um contrato formal, com confiança no relacionamento e sem receio de comportamentos oportunistas (mecanismos de governança), os quais contribuem mais fortemente para a geração de rendas relacionais. 
Para a geração dessas fontes de rendas relacionais, a empresa possui recursos e atividades da cadeia de valor que contribuem para sua vantagem colaborativa. Por exemplo, o recurso intangível de eficiência operacional contribui para a realização das atividades primárias de Operações e Serviços da cadeia de valor da empresa trading. O que, consequentemente, contribui para a geração de rendas relacionais de dotação de recursos complementares entre as duas empresas, visto que a trading atua com sua expertise na gestão do processo de importação e a empresa importadora conhece melhor as características do produto importado, bem como sua forma de manuseio e armazenamento. O que contribui para que o processo seja feito de forma eficiente e efetiva.

Diante do exposto, verifica-se que as empresas possuem uma forte relação de confiança mútua, que gera benefícios comuns que não poderiam ser gerados individualmente, como por exemplo a complementaridade de recursos de conhecimentos sobre o processo de importação pela empresa trading e do conhecimento sobre o produto da empresa importadora.

Cao e Zhang (2011) afirmam que a vantagem colaborativa é resultado de uma vantagem competitiva conjunta. Fortalecer essas fontes de rendas relacionais poderá gerar maiores lucros à empresa a partir de relacionamentos interorganizacionais que fortalecem uma maior agregação de valor no processo de importação de uma carga conteinerizada.

Portanto, observa-se que um desempenho eficiente pela empresa trading de suas atividades, como por exemplo a gestão logística do processo de importação e suas operações de documentação da carga, e de seus recursos o seu relacionamento com stakeholders; e sua experiência nas operações, contribui para um fortalecimento na relação e uma maior geração de vantagens colaborativas e, consequentemente, maior agregação de valor no processo de importação dessa carga, sob a ótica do elo estudado (empresas importadora e trading).

\section{CONSIDERAÇÕES FINAIS}

De acordo com a visão relacional, muitos recursos e capacidades de uma empresa não estão limitadas às fronteiras da empresa, estendendo também a sua rede. Conhecer esses recursos compartilhados é fundamental para o desenvolvimento de vantagens colaborativas, 
a fim de que se possa explorar vantagens competitivas, aprendizado e agrupamento de recursos.

Conhecer a cadeia de valor e seus recursos sobre a ótica da VBR aparece como um importante aspecto para saber como potencializar relações de alianças estratégicas e adquirir maior vantagem colaborativa. Nesse sentido, o presente artigo buscou analisar a cadeia de um processo de importação de uma carga conteinerizada, fazendo um recorte entre os dois agentes de maior interação nessa cadeia, bem como avaliar como as atividades da cadeia de valor e os recursos de uma empresa trading podem impactar na vantagem colaborativa entre ela e uma empresa importadora, agregando valor ao processo.

Conforme evidenciado por Prajogo, Oke e Olhager (2016) em seu estudo, a pesquisa relatada neste artigo também foi capaz de ampliar a VR no contexto de cadeia de suprimentos. Prajogo, Mcdermott e Goh (2008) também argumentam que as empresas que reconhecem que elementos específicos da sua cadeia de valor estão associados a medidas de desempenho que geram vantagem competitiva, têm maior potencial de produzir superioridade competitiva. Tal fato foi evidenciado neste estudo resultante de uma análise empírica que promove a compreensão interorganizacional ao qual resulta vantagem colaborativa e, consequentemente, competitiva.

O presente artigo trouxe algumas contribuições práticas e teóricas. Em termos teóricos, pode-se afirmar que a pesquisa contribuiu para um melhor entendimento sobre gestão estratégica no comércio marítimo. Além disso, apesar de muitos trabalhos abrangerem as teorias de cadeia de valor (PORTER, 1991), VBR (BARNEY, 1991) e VR (DYER; SINGH, 1998), foi observado uma escassez na literatura acerca de uma integração de cadeia de valor com esses temas. Como implicações práticas, o trabalho traz algumas contribuições, como: (i) o reconhecimento da cadeia de valor de uma trading, que contribui para um fortalecimento de sua vantagem competitiva; (ii) os principais recursos que contribuem para essa vantagem sob a ótica da VBR; (iii) as fontes de rendas relacionais que geram vantagem colaborativa do elo estudado entre a trading e a empresa importadora e; (iv) como essas atividades e recursos podem ser aproveitados para uma maior geração de vantagem colaborativa sob o processo de importação de uma carga conteinerizada. 
O trabalho possui como limitações, por exemplo, o fato de se fazer uso de um único estudo de caso como método de pesquisa, o que não permite generalizações. Além disso, foi estudado somente um elo do processo de importação de uma carga e sob a ótica de uma empresa trading apenas. Dessa forma, para futuras pesquisas, sugere-se uma ampliação do escopo desta pesquisa, podendo ser replicado esse estudo para outros elos de um processo de comércio marítimo e sob a ótica de ambas as partes desse elo.

\section{REFERÊNCIAS}

BARALDI, E.; GRESSETVOLD, E.; HARRISON, D. Resource interaction in inter-organizational networks: Foundations, comparison, and a research agenda. Journal of Business Research, v. 65, n. 2, p. 266-276, 2012.

\section{BARNEY, J. B. Firm Resources and Sustained Competitive AdvantageJournal of} Management, 1991. Disponível em: <http://jom.sagepub.com/cgi/doi/10.1177/014920639101700108>

CAO, M.; ZHANG, Q. Supply chain collaboration: Impact on collaborative advantage and firm performance. Journal of Operations Management, v. 29, n. 3, p. 163-180, mar. 2011.

DE MARTINO, M.; CARBONE, V.; MORVILLO, A. Value creation in the port: opening the boundaries to the market. Maritime Policy and Management, v. 42, n. 7, p. 682-698, 2015.

DYER, J. H.; SINGH, H. Cooperative the Relational and Sources of Strategy Competitive Advantage. Academy of Management Review, v. 23, n. 4, p. 660-679, 1998.

FAWCETT, S. E.; FAWCETT, A. M.; MAGNAN, G. M.; MCCARTER, M. W. Why supply chain collaboration fails: the socio-structural view of resistance to relational strategies. Supply Chain Management, v. 20, n. 6 p. $648-663,2015$.

FEIZ ABADI, J.; CORDON, C. Developing a Framework for the Identification and Analysis of the Strategic Resources and Capabilities in Supply Chains. Operations and Supply Chain Management, v. 5, n. 2, p. 59-75, 2012.

GRETZINGER, S.; ROYER, S. Relational resources in value adding webs: the case of a Southern Danish firm cluster. European Management Journal, v. 32, p. 117-131, 2014.

GOHR, C. F. SANTOS, L. C.; BURIN, C. B.; MARQUES; M. S.; ARAI, R. M. Recursos estratégicos e vantagem competitiva: aplicação do modelo VRIO em uma organização do setor sucroalcooleiro. Revista Gestão Organizacional, v.4, n.1, p.116-139 2011.

HALLDORSSON, A.; KOTZAB, H.; MIKKOLA, J. H.; LARSEN, T. S. Complementary theories to supply chain management. Supply Chain Management: An International Journal, v. 12, n. 4, p. 284-296, 2007 
HITT, M. A.; XU, K.; CARNES, C. M. Resource based theory in operations management research. Journal of Operations Management, v. 41, p. 77-94, 2016.

KEEDI, S. $A B C$ do Comércio Exterior: abrindo as primeiras páginas. 4. ed. São Paulo: Aduaneiras, 2012.

KOTLER, P. Administração de marketing. São Paulo: Pearson Prentice Hall, 2000.

JARDIM, A. C.; PERES, V. N.; SANTOS CLARO, J. A. C.; VARANDAS, C. S. P.; BARROS, A. S.; SILVA, E. L. O. Cadeia de Valores: Estudo de Caso Múltiplo em Buffets infantis na Cidade de Santos (SP). Revista Eletrônica de Estratégia \& Negócios, v. 8, n. 1, p. 85-119, 2015.

LAVIE, D. The Competitive Advantage of Interconnected Firms: Academy of Management Proceedings, v. 31, n. 3, p. 638-658, 2006.

LEWIS, M.; SLACK, N.; HOWARD, M. Competing through operations and supply. International Journal of Operations \& Production Management : v. 59, p. 602-614, 2010.

MARCIANO, C.; LEITE, M. S. A.; LUCENA, A. D.; JUNIOR, T. F. G. Evoluindo Da Cadeia De Valor Para Cadeia De Suprimentos Evolving From Value Chain To Supply Chain. Revista Produção Online, v. 10, n. 4, p. 753-778, 2010.

NOVAES, A. G. Logística e gerenciamento da cadeia de distribuição: estratégia, operação e avaliação. Rio de Janeiro: Campus, 2001.

Porter, M.E. (1985), Competitive Advantage: Creating and Sustaining Superior Performance, Free Press, New York, NY.

PORTER, M. Towards a Dynamic Theory of Strategy. Strategic Management Journal, v. Vol. 12, p. 95-117, 1991.

PRAJOGO, D. I.; MCDERMOTT, P.; GOH, M. Impact of value chain activities on quality and innovation. International Journal of Operations and Production Management, v. 28, n. 7, p. 615-635, 2008.

PRAJOGO, D. I.; OKE, A.; OLHAGER, J. Supply chain processes: Linking supply logistics integration, supply performance, lean processes and competitive performance.

International Journal of Operations \& Production Management, v. 36, p. 220-238, 2016.

PRIEM, R.; SWINK, M. Perspective on Supply Chain Management in. Journal of Supply Chain Management, v. 3, n. 2, p. 7-13, 2012.

RODRIGUES, F. C.; ALCANTARA, R. L. C. Visão Baseada Em Recursos E Sua Aplicação Na Gestão Da Cadeia De Suprimentos. XXXV Encontro Nacional de Engenharia de Produção. Anais...Fortaleza, CE: ABEPRO, 2015

SILVA, P. H. M; GOHR, C. F.; LEITE, M. S. A. Vantagens Competitivas de um Porto Marítimo no Nordeste: Uma Análise Segundo a Visão Baseada em Recursos. Revista Eletrônica de Estratégia \& Negócios, v. 11, n. 2, p. 108-130, 2018. 
WILK, E. DE O.; FENSTERSEIFER, J. E. Use of resource-based view in industrial cluster strategic analysis. International Journal of Operations and Production Management, v. 23, n. 9, p. 995-1009, 2003.

YIN, Robert K. Estudo de caso: planejamento e métodos. (2Ed.). Porto Alegre: Bookman. 2001. 